\title{
Influence of sports vision techniques on adult male rugby players
}

\author{
P.J. DU TOIT, ${ }^{1}$ P.E. KRÜGER, ${ }^{2}$ K.F. FOWLER, ${ }^{1}$ C. GOVENDER, ${ }^{1}$ AND J. CLARK ${ }^{2}$ \\ ${ }^{1}$ Department of Physiology, University of Pretoria, Pretoria, South Africa \\ ${ }^{2}$ Department of Biokinetics, Sport and Leisure Sciences, University of Pretoria, Pretoria 0002, \\ South Africa; Email: ernst.Krüger@up.ac.za
}

(Submitted: 12 February 2010 Revision Accepted: 14 July 2010)

\begin{abstract}
Sport has become increasingly competitive and this places enormous pressure on sportsmen to perform at their absolute best. For athletes to achieve their greatest potentials, aspects of sport such as reaction time and hand-eye coordination need to be at their peaks. Sports vision aims to enhance performance through a variety of procedures and training techniques that target basic skills. Twenty six (26) rugby players aged 18 to 26 were subjected to three different sports vision tests. The players were exposed to a period of isolated exercises for physical exertion intervention between the pre- and post sports vision tests. The pre-exercise and post-exercise values of the players were pooled to determine the averages and differences. An improvement in performance was observed by players exposed to these exercises. A significant improvement $(\mathrm{p}<0.05)$ was observed in the number of successful catches and simultaneous ball throw, while a non significant improvement was seen in the number of successful throws through a ring (accurate passing). From the results, it can be seen that there was an improvement in the visual skill performance of the players who were exposed to the specific physical exercises. Athletes are advised to complete at least 15-30 minutes of sport-specific visual training during each day of practice.
\end{abstract}

Key words: Hand-eye coordination, performance, rugby, sport, training, vision.

\section{Introduction}

Coaches and scientists base their choice of physical conditioning and training techniques on the physiological profile and demand of the sport in question. A variety of procedures and training techniques exist in the sporting industry to improve and enhance the performance of athletes. Use of the latest technologies have shaped and guided aspects of sport that have previously been overlooked, making the science of sport that much more complex. One aspect of training that has seen great technological advances is Sports vision.

Unfortunately, little has been published in academic journals regarding the outcomes of Sports vision training and testing. Sports vision involves the training and testing of peripheral vision, visual concentration, hand-eye coordination, reaction time and anticipation in conjunction with optimal training regimes (Abernethy \& Wood, 2001; du Toit, Neves, de Wet \& Krüger, 2007b; Jamara, Potaznick \& Matjucha, 2008). 
There is conflicting evidence between sporting codes as to what level of visual skill is required for success. For example, Abernethy and Neal (1999) argue that supernormal visual skills are not required for success of an elite athlete in clay target shooting. At the most basic level though, it has been shown that peripheral vision has a role in the control of the amplitude of a movement (Lawrence, Khan, Bucholz \& Oldham, 2006) and generally, visual performance is regarded as an important factor for excellence in sport (Haywood, 1984; Granet, 1988; Sale, 1998). Most sporting activities are less effective with poor vision (Wood, Woods \& Jack, 1994). One of the most essential abilities required in sportsmen, particularly those playing team sports, is peripheral vision or awareness (Palmer \& Rosa, 2006).

Eye-hand coordination is the ability of the eyes and hands to work together as a dynamic whole. The process involves sharing information regarding the progress of one sub-movement with the centers controlling another sub-movement, ensuring that the second happens in appropriate relation to the first (Haggard, 1997). Movement in response to stimulus during a game is almost one of the most important features of a good sportsman. If the athlete is unable to dodge a ball, pass and catch a ball, manoeuvre around a squash court or react to a spin ball, then they will not succeed in their sport. Since sport is typically performed under temporal constraints and varying levels of physiological stress / fatigue, attempts should be made to examine visual function under more realistic test conditions (Williams \& Horn, 1995).

Anticipation is properly the hardest element of sports vision to test, because you need a person to match the game situation. That is why it is important to have multiple dependent measures of performance or several methodological approaches (recall, recognition, eye movements, etc.) when measuring anticipation and decision-making in sport (McPherson, 1994; Weissensteiner, Abernethy, Farrow \& Muller, 2008).

This pilot project was aimed at determining whether short-term application of sports vision exercises under routine training conditions can influence sports vision skills.

\section{Materials and methods}

The 26 players, aged 18 to 26 years, were recruited from a rugby academy. The testing was requested by the academy and permission was granted for the use of the data.

To evaluate the effects of specific sports vision exercises on hand-eye coordination, a pre- and post-test experimental group design was adopted for the study. All players were subjected to a repeated measure protocol using three 
different hand-eye coordination tests. The players were exposed to a period of isolated exercises for physical exertion intervention between the pre- and posthand-eye coordination tests. Each player served as his own control.

\section{Heart Rate Monitoring}

Monitoring heart rate is an easy and reliable method for determining effort during exercise. A general aerobic training intensity of $82 \%$ of maximal heart rate was calculated using heart rate, blood lactate and oxygen consumption as indicators to determine training intensity (du Toit, de Wet, van Vuuren \& Rossouw, 1999). Using this specific aerobic training intensity, a good aerobic fitness base could be achieved without applying unnecessary stress on the body, thus decreasing risk of injuries as well as limiting the effects of fatigue which could have affected post-test results. The Hosand TM 200 HR telemetry 30 real time wireless heart rate monitoring system was used as a means of monitoring physical activity by enabling one to set clear, precise and observable limits on physical activity which are, to a degree, able to be self-controlled.

The sports vision testing protocol comprised three specific hand-eye coordinated tests, which was used to evaluate different parameters of hand-eye co-ordination. The operational definitions, in conjunction with the procedures, instruments and scoring applied in the testing, were as follows:

\section{Sports vision test:}

Alternative hand wall toss - modified simultaneous ball throw

Participants must stand facing a wall behind a $2 \mathrm{~m}$ retaining line, holding a tennis ball in the right or left hand. Two extra balls are stored in a nearby container. Knees should be slightly bent and feet shoulder width apart. On the starting signal, the player tosses the tennis ball in an under-arm motion from the right hand against the wall and catches it with the left hand. It is then thrown with the left hand and caught with the right. This movement is repeated as often as possible in thirty seconds and the number of successful catches is recorded. The parameters tested in this specific test included visual concentration, reaction time, flexibility, agility and hand-eye co-ordination which is very important in testing rugby players (Woodman, 1985; Hahn, 1990; Bloomfield et al., 1994).

\section{Accurate passing}

The Passing for accuracy test evaluates peripheral awareness, anticipation, and visual concentration. A circle target is placed four meters away and parallel to the line run by the player. The circle target is at the chest height that balls are usually passed during a rugby match. While running with a rugby ball, the player 
throws the ball through the circle (4m away) as if passing it to another player. One point is awarded for every successful pass through the circle. The player has five chances to pass the ball through the circle from the left and five from the right. The score is recorded. In order to prevent players from learning one another's passing styles and cues partners were rotated for every exercise (Pienaar, Spamer \& Steyn, 1998).

Simultaneous Ball Throw out of both hands:

This test assesses a player's peripheral vision, visual concentration and hand-eye coordination. Two players stand two meters apart, facing one another, with knees slightly bent and feet shoulder width apart. Player one holds a tennis ball in each hand and throws both balls simultaneously in an underarm fashion for player two to catch. Player two must catch a ball in each hand. Player two then tosses the balls to player one. The two players continually toss the balls between each other for a period of two minutes and the number of successful catches is counted (du Toit, Krüger, Joubert, Lunsky, 2007a).

\section{Sports vision exercises}

Four sports vision improvement (lateral shuffle and ball catch, ball drop, turn and catch and push-up to catch) exercises were chosen for this research. A number of different exercises do exist and more advanced version of the exercises can be incorporated into training as the athletes progress (du Toit et al., 2007a). In the Lateral shuffle and ball catch, which improves eye-brain-body coordination and visual concentration, player one stands between two cones four meters apart and player two stands two meters in front of player one with a tennis ball in hand. Without being too predictable, player two throws the ball in either direction towards the cones while player one anticipates the direction of the ball, shuffles in the direction of the ball, catches it then throws the ball back to player two. The two players continually toss the balls between each other for a period of two minutes (du Toit et al., 2007a).

In the Ball drop, player one stands upright with a rugby ball held out at head height while player two stands facing player one. As player one shouts 'catch!' he drops the ball and player two has to squat and catch the ball with palms below the ball facing inwards. Player two returns to standing position, throwing the ball back to player one. This is repeated for a minute per player. This exercise is aimed at improving peripheral vision and foot speed (du Toit et al., 2007a).

In the push-up to catch exercise, player one is in the push-up position while player two stands in front of player one with a rugby ball. Player one completes a full push-up while player two throws the rugby ball giving player one just enough time to stand up and catch the ball between each push-up. In this 
exercise, the players require quick movement to get into position to make the catch as well as fast focusing of the eyes on the ball. This is repeated for a minute per player.

Player one (turn and catch) stands with his back to player two. They are $4 \mathrm{~m}$ apart. On command from player two, player two throws a rugby ball while player one turns around to catch the ball, facing player two. This is a good exercise to improve reflexes.

Aside form the sports vision pre- and post-tests and the sports vision exercises, a regular training routine was followed. The routine included sit-ups, push-ups, squat jumps, dips, jumping jacks, static hold-run, run-pushup-reverse and squat thrusts. The routine supports the findings of several researchers (Woodman, 1985; Hahn, 1990; Bloomfield et al., 1994) that aspects of somatotype, body composition, proportionality, strength and power, flexibility, speed, posture, coordination, balance and agility should be considered for inclusion in tests.

The continuity of a regular training routine is seen as an important aspect of integrating sports vision training and testing into the players' training lifestyles. The training allowed simulation of the on-field factors that could influence sports vision skills, e.g. physical exhaustion. Some players battled to complete the full fitness exercise routine as fatigue set in. However, all of the sports vision exercises were completed. The exercises were carried out over three days.

\section{Statistical Analysis}

The pre- and post-test results of the players were pooled for analysis. Data were analysed using SPSS version 17.0. Descriptive statistics (mean \pm SD) were used to describe the sample and performances. A pre- and post-test performance comparison was carried out using the Paired Samples T-test $(\mathrm{p} \leq 0.05)$.

\section{Results}

The mean age of the sample was 21.31 years (SD 2.29). The results of the preand post-test tasks and the paired samples t-test analysis are shown in Table 1. Significant differences in pre- and post-test performances are denoted by an asterisk. There was a significant difference in the players' alternative hand walltoss and simultaneous ball throwing tests. 
Table 1: The mean and standard deviations for alternative hand wall-toss, passing for accuracy (left and right) and simultaneous ball throwing

\begin{tabular}{lccc}
\hline Variable & Mean & Std. Deviation & p-value \\
\hline Alternative hand wall-toss pre-test & 30.33 & 3.75 & $<0.05^{*}$ \\
Alternative hand wall-toss post-test & 33.83 & 4.529 & \\
Passing for Accuracy Left Pre-test & 3.08 & 0.900 & 0.220 \\
Passing for Accuracy Left Post-test & 3.38 & 1.121 & \\
Passing for Accuracy Right Pre-test & 2.69 & 0.855 & 0.337 \\
Passing for Accuracy Right Post-test & 3.08 & 0.954 & \\
Simultaneous Ball Throwing Pre-test & 67.00 & 27.224 & $<0.05^{*}$ \\
Simultaneous Ball Throwing Post-test & 86.23 & 24.321 & \\
\hline
\end{tabular}

\section{Discussion}

In order to measure the athletic ability of a sporting individual, it is important not to only measure the cardiopulmonary and metabolic status (West, Williams, Wilkins, 1989; Wasserman, 1996) of the individual but also his/her hand-eye coordination. It is well known that environmental demands are matched by taskspecific motor responses and an extension of this theory shows that visual ability can influence performance. The nature of such visual involvement will vary according to environmental demands (du Toit et al., 2007b).

Just as physical exercise and practice increases strength and speed, visual performance might also be improved to achieve maximum results (du Toit et al., 2007a). Since sport is typically performed under temporal constraints and varying levels of physiological stress or fatigue, attempts should be made to examine visual function under more realistic test conditions (Williams \& Horn, 1995).

The specific exercises used in this experimental group lead to an improvement in the post tests, which suggested an improvement in hand-eye coordination, accuracy, visual response speed, short visual memory, anticipation and visual concentration. As well as improvement in physical performance, the results obtained in this study confirm the possibility that moderate intensity exercise also improve mental performance (Paas \& Adam, 1991).The results also suggest that hand-eye coordination is sensitive to the short-term effects of exercise, mediated by several factors (Tomporowski \& Ellis, 1986), such as physical 
fitness of subjects, intensity and duration of the exercise intervention, skills (Chow, Davids, Button \& Koh, 2008) and the coordination tests selected.

\section{Conclusion}

This study was carried out in order to determine the influence of sports vision techniques on adult male rugby players. The results indicate that visual skills tend to increase after the specific exercise intervention period. Sports vision is an integral part of the holistic approach to improve performance on the field and should not be taken for granted. Further studies using a larger sample size is recommended to evaluate the visual skills on a more extensive level.

\section{References}

Abernethy, B. \& Neal, R.J. (1999). Visual characteristics of clay target shooters. Journal of Science and Medicine in Sport, 2 (1), 1-19

Abernethy, B. \& Wood, J.M. (2001). Do generalized visual training programmes for sport really work? An experimental investigation. Journal of Sports Sciences, 19(3), 203-222.

Bloomfield, J., Ackland, T.R. \& Elliot, B.C. (1994). Applied anatomy and biomechanics in sport. Melbourne: Blackwell Scientific.

Chow, J.Y., Davids, K., Button,C. \& Koh, M. (2008). Coordination changes in a discrete multiarticular action as a function of practice. Acta Psychologica, 127(1), 163-176.

du Toit, P.J., de Wet, K.B., van Vuuren, B. \& Rossouw, J. (1999). Calculating an aerobic endurance training intensity for cricket players in the off-season. African Journal for Physical, Health Education, Recreation and Dance, 6(2), 190-203.

du Toit, P.J., Krüger, P.E., Joubert, A. \& Lunsky, J. (2007a). Effects of exercise on the visual performance of female rugby players. African Journal for Physical, Health Education, Recreation and Dance, 13(3), 267-273.

du Toit, P.J., Neves, R., de Wet, K.B. \& Krüger, E. (2007b). Exercise, performance and sport vision testing. African Journal for Physical, Health Education, Recreation and Dance (Supplement), December 2007, 140-149.

Granet, D.B. (1988). Objectivity in sports vision testing. International Ophthalmology Clinics, 28, 197-198.

Haggard, P. (1997). Coordinating actions. Quarterly Journal of Experimental Psychology, 50(4), 707-725.

Hahn, A. (1990). Identification and selection of talent in Australian rowing. Excel, 6, 5-11. 
Haywood, K.M. (1984). Use of the image-retina and eye-head movement visual systems purring coincidence-anticipation performance. Journal of Sports Sciences, 2, 139-144.

Jamara, R., Potaznick, W. \& Matjucha, I. (2008). Low vision rehabilitation for a target-shooting marksman with visual field loss and diplopia. Optometry, 79(5), 235-240.

McPherson, S.L. (1994). The development of sport expertise: Mapping the tactical domain. Quest, 46, 223-240.

Lawrence, G.P., Khan, M.A., Buckolz, E. \& Oldham, A.R.H. (2006). The contribution of peripheral and central vision in the control of movement amplitude. Human Movement Science, 25(3), 326-338.

Paas, F.G.W.C. \& Adam, J.J. (1991). Human information processing during physical exercise. Ergonomics, 34, 1385-1397.

Palmer, S.M. \& Rosa, M.G. (2006). A distinct anatomical network of cortical areas for analysis of motion in far peripheral vision. European Journal of Neuroscience, 24(8), 2389-405.

Pienaar, A.E., Spamer, M.J. \& Steyn, H.S. (1998). Identifying and developing rugby talent among 10-year-old boys: A practical model. Journal of Sports Sciences, 16, 691-699.

Sale, D.G. (1998). Neural adaptation to resistance training. Medicine and Science in Sports and Exercise, 20, S135.

Tomporowski, P.D. \& Ellis, N.R. (1986). The effects of exercise on cognitive processes: A Review. Psychological Bulletin, 99, 338-346.

Wasserman, K. (1996). A new method for detecting anaerobic threshold by gas exchange. Journal of Applied Physiology, 60, 2020-227.

Weissensteiner, J., Abernethy, B., Farrow, D. \& Muller, S. (2008). The development of Anticipation: A cross-sectional examination of the practice experiences contributing to skill in cricket batting. Journal of Sport \& Exercise Psychology, 30, 663-684.

West, J.B., Williams, J.G. \& Wilkins, K. (1989). Physiological Basis of Medical Practice (pp. 729-53). London.

Williams, J.G. \& Horn, R.R. (1995). Exercise intensity effects on peripheral perception of soccer player movement. International Journal of Sports Vision, 2(1), 22-28.

Wood, J.M., Woods, R.L. \& Jack, M.P. (1994). Exercise does not increase visual field sensitivity. Optometry and Vision Science, 71, 682-684.

Woodman, L. (1985). Talent identification - Is competition enough? Sports Coach, 9, 49-57. 